\title{
Openness and management systems integration: pursuing innovation benefits
}

\begin{abstract}
In an increasingly competitive world, firms are continuously challenged to benefit different stakeholders through an efficient innovation process using limited resources. To this end, the Integration of Management Systems (IMS) and Open Innovation (OI) are two managerial practices analyzed in this study as potential drivers of innovation efficiency. The longitudinal analyses of 220 Spanish firms suggest that IMS enables innovation efficiency, whilst OI might deliver some manageable inefficiency. Moreover, innovation efficiency has a positive impact on the sales productivity of new products. This is one of the first articles to study jointly these managerial practices in pursuit of innovation benefits.
\end{abstract}

Keywords Innovation Efficiency; Management Systems Integration; Open Innovation; Firm Performance

Paper type Research paper 


\section{Introduction}

In a challenging world dominated by fast changes, firms are pushed to innovate efficiently, optimizing their limited resources to benefit their stakeholders through new products or processes (West and Anderson, 1996; Wong et al., 2009). It is thus a primary managerial challenge to attain an efficient innovation process so that firms can keep growing. Stated differently, firms should adopt the accurate managerial practices that boost innovation efficiency and consequently, expect to grow sustainably.

Guided by efficiency, firms should produce the appropriate outputs that pay off the resources used in the innovative process (Fichman, 2004). Not only the firms' internal tradeoffs are important in this process, but also their own performance compared to their key competitors'. In this line, innovation efficiency is defined as the relative efficiency of firms for transforming resources (inputs) into innovations (outputs) (Deprins et al., 1984), so firms that are more efficient innovating might achieve more internal and external benefits as follows. Firms innovating efficiently use less resources to innovate (Cruz-Cázares et al., 2013; George et al., 2002; Greco et al., 2017) and create a stronger innovative basis due to their learning capabilities (Weerawardena et al., 2006). Once firms increase their innovation efficiency (i.e., the process of transforming resources into innovations), they might enhance their performance due to the commercialization of such innovations, which occurs in a second stage (Guan and Chen, 2010; Wang et al., 2016; Wang and Wang, 2012). Therefore, firms innovating efficiently might also achieve better sales productivity results when commercializing their new products (de Leeuw et al., 2014).

The OECD (2008) highlights that organizations operate within a high global competition environment so innovations are becoming riskier and costlier. This challenging landscape has led firms to increasingly open their innovation processes to collaborate with external partners, including suppliers, customers, universities, among others (OECD, 2008). This paradigm, referred to as open innovation (OI), describes how firms interact with external organizations to attain their innovation goals using less resources and exploiting those new outcomes in the market (Chesbrough, 2007, 2003). OI is therefore aimed to improve innovation efficiency. More specifically, a firm can be defined as more efficient in its OI approach than another if it obtains better innovation outputs starting from similar OI inputs (Greco et al., 2017). Although the existing literature about OI is very extensive (Lopes and 
de Carvalho, 2018), the concept of innovation efficiency in the OI literature is surprisingly an under-researched topic (Greco et al., 2017).

Besides seeking innovation efficiency through OI, firms should also focus on their internal procedures. Management systems (MSs) describe such procedures, which are aimed to enable the fulfillment of specific objectives related to quality, environment, among others (ISO, 2017a). In the innovative process, these aspects should be considered and integrated for achieving the requirements of the new developments (von Ahsen, 2014). Since each individual MS is very specific and narrow in scope, their integration is a primary managerial task to optimize resources and results (Bernardo et al., 2009; Jørgensen et al., 2006; Salomone, 2008). Therefore, this research focuses on the role of IMS as a potential driver of innovation efficiency, which relationship in literature remains scarcely explored (Nunhes et al., 2016). Due to their relevance to this topic, this study focuses on Quality MSs (QMSs) (Palm et al., 2016), and its integration with Environmental MSs (EMSs) (Simon et al., 2014; von Ahsen, 2014).

This research aims to study the roles of IMS and OI in pursuit of innovation efficiency, so firms can attain a better performance. In this effort, firstly innovation efficiency is analyzed in the context of IMS. Secondly, the relationship between innovation efficiency and firm performance is analyzed from the viewpoint of innovative sales productivity. Finally, this study analyzes the role of OI in the relationship between innovation efficiency and firm performance.

\section{Theoretical Framework}

Since efficiency was proposed as a relevant measure to assess how resources are optimized to produce outputs (Deprins et al., 1984), its application on innovation has become increasingly important to countries (Acs et al., 2002; Drivas et al., 2018; Guan et al., 2016; Guan and Chen, 2010; Liu et al., 2017) and firms (Cruz-Cázares et al., 2013; Hashimoto and Haneda, 2008; Wang et al., 2016). These studies highlight the need of measuring innovation efficiency in order to optimize firm performance, but few have focused on the implications of implementing both managerial practices, IMS and OI (Hernandez-Vivanco et al., 2016). 


\subsection{The Integration of Management Systems as a driver of Innovation Efficiency}

In pursuit of innovation, the knowledge-based view theory (Grant, 1996) postulates that firms must stablish the necessary coordination links that enable the specialists' knowledge integration. Nonetheless, this task involves several challenges, and minimizing goal conflicts between the different actors is critical. From a complementary perspective to deal with this challenge, MSs are defined as "the way in which an organization manages the inter-related parts of its business in order to achieve its objectives” (ISO, 2017a). Thus, MSs should facilitate the links that enable knowledge integration through the accurate management of the different, but still inter-related parts of the business. Moreover, MSs are focused on achieving the business objectives, so they are intended to optimize firms' resources, which should enhance innovation efficiency (Matias and Coelho, 2011). However, this relationship remains unclarified for QMSs and EMSs, as discussed next.

Several studies have found that a positive relationship between QMSs and innovation is conditioned to factors such as: i) the cultural changes achieved through its implementation (Moreno-Luzon et al., 2013), ii) only specific dimensions of the MS including leadership and people management (Hoang et al., 2006; Prajogo and Sohal, 2004), and iii) firms’ openness (Hoang et al., 2006), among others. Others state that virtually every dimension of QMSs is positively related to innovativeness (Kim et al., 2012; Perdomo-Ortiz et al., 2006) whilst a final trend is opposite, and suggests they are detrimental to innovation (Prajogo and Sohal, 2001).

A similar scenario can be found in the EMSs literature. Radonjic \& Tominc (2006) suggest EMSs are catalyzers of technological innovations, in accordance to Wagner (2008). Other studies suggest positive associations with certain types of innovations (Wagner, 2007a; 2008), although such relationships could turn into negative if EMS is not diffused across the organization (Prajogo et al., 2014). Lastly, Ziegler \& Seijas Nogareda (2009) found no clear causality.

Despite the lack of consensus of the existing literature analyzing QMSs and EMSs independently, there seems to be less disagreement about the positive relationship between their integration and innovation (Bernardo, 2014; Nunhes et al., 2016). Thus, the role of IMS in the innovative performance is further developed based on the knowledge-based view theory. 
IMS intends to unify several function-specific MSs (Jørgensen et al., 2006) into one system (Karapetrovic, 2003). The derived integrated control allows firms to increase their competitiveness by focusing on their performance (Renzi and Cappelli, 2000). In this process, firms should first integrate the individual MSs' goals (Bernardo et al., 2009; Jørgensen et al., 2006; Nunhes et al., 2017; Salomone, 2008), which is also one of the most complex management issues according to the knowledge-based view. By this means, IMS contributes to the optimization of resources (Abad et al., 2014; Salomone, 2008; Santos et al., 2011) and, analogously to the enhancement of 'organizational' efficiency (Nunhes et al., 2016; Simon and Douglas, 2013), it could boost ‘innovation’ efficiency. Such benefits would become more noticeable as IMS levels increase; i.e., when firms integrate their most strategic goals, which leads to the extensive implementation of IMS across the firm, including operations and tactics. Thus, firms that integrate all the aspects of the individual MSs are fully integrated as opposite to those that manage each MS independently, called nonintegrated (Bernardo et al., 2009).

Regarding the relationship between IMS and innovation efficiency, Matias \& Coelho (2011) showed preliminary empirical results about the critical role of IMS as the starting point of innovating with added efficiency. The authors support that, through IMS, firms take advantage of the compatibility of the individual MSs. As a result, they reduce the amount of resources needed to pursue the goals of each of the systems, which are also closely related between them since all MSs pursue continuous improvement (i.e., promote innovation). According to the authors, firms that fully integrate their MSs locate innovation at the core of the integrated pool to promote widespread company innovation and the creation of competitive advantages. The authors also discuss that IMS promotes improving the management of resources, cost reduction and increased results, including those related to innovation. Therefore, IMS seems to be closely related to innovation efficiency.

Bernardo (2014) supported theoretically the previous empirical results, and associated IMS with an enhanced innovation performance. Since IMS is itself an organizational innovation, its positive relationships with the whole innovative performance is due to: i) the integration of the benefits from each MS, ii) the introduction of new products/processes, iii) the development of new capabilities, and iv) the pursuit of an increased performance of the firm. 
Although scarce empirical research has been done to support the previous arguments, innovation efficiency-oriented studies report that innovation capabilities allow its improvement (Guan et al., 2006). Such capabilities could be particularly influenced by the full IMS (Hernandez-Vivanco et al., 2016). Consequently, by fully integrating MSs, resources could be more efficiently used to produce innovation outputs. Thus, H1 is formulated:

H1: The full integration of management systems is positively related to higher levels of innovation efficiency.

\subsection{Innovation Efficiency and Firm Performance}

Relating innovation efficiency and firm performance is not a novel approach (CruzCázares et al., 2013). However, the empirical evidence relating them in the context of this paper is still limited and requires further examination. To this end, and guided by the definition of innovation efficiency, the effects of: i) innovation inputs, ii) innovation outputs, and iii) innovation efficiency (i.e., considering the process of transforming innovation inputs into outputs) on firm performance are analyzed next.

Focusing on innovation inputs, George et al. (2002) found that firms can expend less resources for producing more outputs if they exploit their knowledge strengthening the links between the people involved in the innovative process. Weerawardena et al. (2006) complemented such results and reported that firms can enhance their learning capabilities, especially in competitive industries, to promote innovation though the optimization of resources. Nonetheless, Koellinger (2008) warned that if inputs do not result into outputs, firm performance may not be directly improved by inputs.

Outputs by themselves could directly produce negative effects on firm performance if companies are not able to compensate the costs needed to produce or protect them (CruzCázares et al., 2013). In fact, according to the authors, relating innovation outputs to performance without considering the effort - innovation inputs - required to produce those innovation outputs might lead to a skewed perspective. As a result, improving performance seems to be more linked to the efficiency of transforming innovation inputs into outputs rather than to each individual perspective of inputs and outputs separately. This is mainly due 
to the complexity of the innovative process, which is not only related to inputs or outputs as isolated factors (Tidd and Bessant, 2009).

Considering both innovation inputs and outputs, Klomp \& Van Leeuwen (2001) discussed that even if innovation is important for the economic activity, it cannot be stated $a$ priori that innovative firms perform better than non-innovative. Instead, it is the innovative process what leads to an enhanced overall performance. Although the authors made a significant progress in this field, they did not consider inputs and outputs from an efficiency perspective.

Regarding studies focused on innovation efficiency -as the efficiency to transform innovation inputs into outputs- different approaches have been applied. In some cases, efficiency has been considered beyond the innovation practices by including measurements of performance as part of the outputs, such as market share, sales of new products, exports, profits, productivity, among others. In this line, Guan et al. (2006) focused on Chinese firms and revealed that companies that innovate efficiently benefit of an enhanced competitiveness. According to the authors, this is particularly true when the invested inputs are proportional to firm performance, which is generally the case. Conversely, if outputs exceed significantly to innovation inputs, such relationship is no longer significant. This might suggest that, to most firms, their performance is directly related to their innovation efficiency, while a minority attain a better performance through other mechanisms not directly related to it. Later, Hashimoto \& Haneda (2008) applied a similar approach in the Japanese pharmaceutical industry. The authors concluded that firms were inefficient when their innovation expenditures increase at a different rate compared to their sales of new products and technology. Thus, to benefit of innovation efficiency, firms should focus on the efficient use of their innovative resources to produce innovations and subsequently on the sales of the resulting innovation outputs.

The previous results suggest that there might be a close relationship between innovation efficiency and firm performance. Following this reasoning, Guan and Chen (2010) considered that the innovation process was subdivided into two stages, namely the R\&D and the commercialization sub-processes. Interestingly, their results unveil an unexpected matching relationship between both sub-processes, concluding that firms and governments must promote the whole process from innovation to final commercial outcomes so that 
innovating efficiently can be profitable. Concurrently, Wang and Wang (2012) reported that firms innovating more efficiently perform better than their competitors. Cruz-Cázares et al. (2013) focused on this relationship and produced one of the first papers to state a positive causality between innovation efficiency and firm performance. The authors argued that firms that innovate efficiently perform better due to their proficiency for transforming innovation inputs into innovation outputs. As conferred previously, this would promote firm performance through the correspondence of the commercial activities.

More recently, Wang et al. (2016) went deeper into the relationship between innovation efficiency and firm performance in commercial terms. The authors focused on the Chinese energy industry and found that, in some cases, firms that devote excessive efforts to increase their performance could potentially jeopardize innovation efficiency. The authors highlight that, in order to prevent such a risk, firms should implement managerial strategies to promote first their innovation efficiency and subsequently their performance. Thus, in the context of this study, innovation efficiency can be discussed to positively affect firm performance as stated in hypothesis H2:

H2: Innovation efficiency has a positive effect on firm performance.

\subsection{The role of Open Innovation}

In the early stages of the OI literature, Chesbrough (2007) discussed the increasing difficulty of traditional (closed) companies to justify innovation investments due to the rising of development costs and shorter life cycles. Thus, OI emerged as a model that promotes new ways to use outer knowledge and technologies. More specifically, it allows the optimization of innovation inputs (i.e., promotes innovation efficiency) through such external sources, improving and enriching the existing knowledge base (Laursen and Salter, 2006). This would also allow the creation of new products that can be commercialized externally (Chesbrough, 2007).

According to Chesbrough and Bogers (2014), open firms can have inflows and outflows of knowledge. Through inflows, external knowledge sources act as levers of internal processes, which might improve innovation efficiency through the optimization of the additional knowledge. To this end, firms must plan and balance in-depth both their internal and external resources (Geum et al., 2013). Complementary, outflows are mainly the result 
of the internal knowledge being leveraged through external commercialization processes, resulting in the enhancement of their performance in commercial terms (Chesbrough and Bogers, 2014). Thus, in OI, both inflows and outflows are compatible by coupling external knowledge sources (which foster innovation efficiency) and commercialization activities. Therefore, as a global hypothesis derived directly from the basis of OI, H3 is formulated as follows:

H3: Firms that adopt open innovation optimize their innovation efficiency. This, in turn, leads efficient firms to improve their performance.

The previous hypothesis requires further examination in the context of this paper. To this end, firstly the relationship between OI and innovation efficiency is discussed followed by the role of OI on the effects of innovation efficiency on firm performance.

Chesbrough and Bogers (2014) highlighted that OI is intended to be in line with the organization's business model. As stated previously, such structure would be involved in the firms' procedures described by MSs (ISO, 2017a). Thus, OI and IMS should be compatible managerial practices leading to increase innovation efficiency.

Despite the scarce literature analyzing OI and MSs together, the existing empirical evidence seems to be in line with the previous arguments. Related to QMSs, Hoang et al. (2006) found that open organizations achieve a better innovation performance, supported on the quality aspects related to leadership, people management, process and strategic management. Similarly, Gavronski et al. (2012) found that when firms implement EMSs, the knowledge generated from external cooperation acts as a trade-off factor towards the adoption of new technologies and innovation. Such a compatibility also occurs when analyzing OI in the context of IMS. In fact, OI could coexist in synergy with IMS, increasing innovation capabilities (Hernandez-Vivanco et al., 2016), which are particularly useful to improve innovation efficiency (Hashimoto and Haneda, 2008).

In the context of this paper, it seems that OI might foster innovation through the optimization of resources attained through the development of the internal knowledge base (Laursen and Salter, 2006), and the enhanced innovation capabilities gained with it (Behnam et al., 2018; Cheng et al., 2016). This might result into open firms using less resources to obtain more innovation outputs, and therefore, in an increased OI efficiency (Greco et al., 
2017). Hence, companies that practice OI use their resources more efficiently, as stated in Н3а:

H3a: Open innovation in firms is positively associated with innovation efficiency.

Regarding the role of OI in the relationship between innovation efficiency and firm performance, several studies had been conducted with different backgrounds, but their relationship is still far from being conclusive and requires further research (Lopes and de Carvalho, 2018). When OI was in the early stages, authors like Klomp and Van Leeuwen (2001) and Belderbos et al. (2004) found that cooperating with different external sources fosters radical innovations through the complementation of the internal activities. Although such studies did not go deeper into the mechanisms later proposed by Chesbrough (2007), the authors found that external collaborations improve firm performance in commercial terms, more specifically in terms of sales productivity.

Chesbrough (2007) considers that OI allows companies to capitalize their inventions through new sales. As a result, firms would increase their revenues exploiting new brands, creating spin-offs, licensing new products and generating new sales. Accordingly, Laursen and Salter (2006) found that although OI is an efficient way of innovating, an excess of ideas could lead to time and management problems that could potentially hinder this positive relationship. Complementing the previous work, Greco et al. (2016) found that firms collaborating deeply with their sources can persistently obtain better results due to their high compromise to succeed jointly. To this end, firms are challenged to allocate the resources and efforts to innovate in a way that OI can be managed efficiently (Ahn et al., 2017).

Since OI emerged as a tool to increase innovation efficiency, firms adopting it might be able to balance their resources and perform better (Lopes and de Carvalho, 2018). This strategy might be of particular relevance to open firms in order to enhance the performance results through innovation (Wang et al., 2016). Thus, H3b is developed:

H3b: The positive effect of innovation efficiency on firm performance is higher for firms that practice open innovation than for closed firms.

Figure 1 schematizes the model to be tested: 
Insert Figure 1 about here

\section{Methodology}

\subsection{Data and sample}

Spanish firms are of special interest since this country has been in the first positions of the top 10 ranking of the most certified countries in the world in ISO 9001 and ISO 14001 MS standards, according to the ISO survey data (ISO, 2017). Based on the number of certifications and the time that Spanish organizations have been working with these MS standards, it is a country in which a great number of companies integrate their MSs into a single and more efficient IMS (see e.g., Bernardo et al., 2009). IMS is considered an organizational innovation and a factor that promotes other types of innovation according to the existing literature (Bernardo, 2014; Jørgensen et al., 2006; Salomone, 2008). Within this context, Spanish firms tend to conceive innovation as being increasingly open and collaborative, and the use of OI is also encouraged in the Spanish national innovation MS standard, UNE 166002 (Garechana et al., 2017). This, together with other MSs, can be hosted in the widely adopted IMS (Mir et al., 2016). Therefore, Spanish firms are of special interest to this study due to their familiarity with IMS and their increasing interest on adopting OI.

The Spanish Innovation Panel, PITEC ${ }^{1}$, is selected for the analysis. It is compiled by the Spanish National Statistics Institute in collaboration with the Spanish Science and Technology Foundation and the Foundation for Technological Innovation. This panel survey registers data of the European Community Innovation Survey (CIS) in Spain. Therefore, the sampling methodology and the harmonized questionnaire are described in the OECD Oslo Manual (OECD, 2005). Given the rigorous application of the CIS survey across countries and companies, it has been widely used in the innovation literature (see e.g., Cruz-Cázares et al., 2013; de Leeuw et al., 2014; Greco et al., 2017).

1 The PITEC database is available free of charge for researchers in https://icono.fecyt.es/PITEC/Paginas/descarga_bbdd.aspx. Further methodological details regarding the actualization, accessibility and coding of PITEC can be found in https:/icono.fecyt.es/PITEC/Documents/2016/DatabasePITEC\%20(Septiembre\%202016).pdf. 
The PITEC dataset was cleaned according to the criteria of the efficiency indicators detailed in the next subsection. All missing values with no consecutive information for at least two years were eliminated. As a result, a total of 570 observations from 220 companies of 13 industries (2 digit CNAE-93 code) were analyzed from 2003 to 2007 due to the availability of data included exclusively in this period. This occurs since the PITEC survey varies some questions across years.

\subsection{Measurement of innovation efficiency}

A benchmark of the innovative performance represents an accurate measure of innovation efficiency, so it is measured as the relative efficiency of firms for transforming innovation inputs into outputs (Deprins et al., 1984). In this study, inputs are related to the investments and human resources used to innovate, whilst innovations are considered as the indicators for the outputs of the innovative process (Cruz-Cázares et al., 2013; Guan et al., 2016; Guan and Chen, 2010; Hashimoto and Haneda, 2008; Wang et al., 2016). According to the innovation efficiency literature, this research is based on proxies for measuring innovation inputs and outputs.

\subsubsection{Inputs selection}

The chosen inputs are Innovation Capital Stock (ICS) and the number of persons involved in the innovative process. ICS considers all the innovation expenses (Hashimoto and Haneda, 2008), which are highly correlated with knowledge generation (Romer, 1991). ICS is consistent with other studies using R\&D Capital Stock as a proxy of Knowledge Stocks (see e.g., Guan et al., 2016) and it is used as a measure of innovation knowledge generation as shown in Equation 1. A conventional depreciation $(\gamma)$ of $15 \%$ for low and medium technology industries and of 30\% for high technology (see e.g., Cruz-Cázares et al., 2013) for each set of two years from 2003 to 2007 is considered, where $I C_{i t}$ represents the Innovation Capital Expenses of firm $i$ at time $t$ :

$$
\text { (Equation 1) } I C S_{i t}=I C_{i t}+(1-\gamma) I C_{\mathrm{i}(t-1)}
$$

The second input includes the number of persons involved in the innovative processes (Hashimoto and Haneda, 2008; Wang et al., 2016). This is equivalent to measuring the R\&D human resources (Guan and Chen, 2010; Lee et al., 2010) at all stages of innovation. Other 
studies have focused on the number of high skilled staff (Cruz-Cázares et al., 2013) and full time researchers (Guan et al., 2016); however, this measurement already englobes all the human resources involved in the innovation process.

\subsubsection{Outputs selection}

Process, product and organizational innovations are outputs of the innovative process. Patents are used as an indicator of product and process innovations. They have been previously used as a proxy for technological innovations (Cruz-Cázares et al., 2013) and R\&D Knowledge Stocks (Guan et al., 2016). Moreover, they are a reliable indicator of firms’ innovative activity (Guan and He, 2007) and of the quality of their innovations (Griliches, 1990). Thus, the number of patents represent an accurate R\&D output (Acs et al., 2002; Cruz-

Cázares et al., 2013; Guan and Chen, 2010) and can be therefore used as a good proxy for economically profitable ideas resulting of the innovation process (Drivas et al., 2018).

Process innovations bring with it significantly improved production methods (OECD, 2005), and most are intended to lower the cost of production (Hashimoto and Haneda, 2008; Klepper, 1996). To this end, firms must invest in innovation to improve their production capacity, which is a suitable strategic decision due to the improvement of the bargaining position gained through it, even when it might affect the efficiency of the system (Plambeck and Taylor, 2005). Thus, the importance of improving the production capacity is used as an output mainly related to process innovations. Respondents of the PITEC survey could choose among four possibilities, reporting this importance as null, low, medium or high.

Finally, the level of IMS is considered as a specific case of organizational innovation (Bernardo, 2014; Jørgensen et al., 2006; Salomone, 2008) and is thus included as an output of innovation. Among the several taxonomic schemes for classifying the level of IMS, Zeng et al. (2007) analyzed it at different stages of a company. According to the authors, at the strategic level the MSs objectives are given the top priority, which determines IMS at more operational stages. Thus, this study focuses on the strategic stage as a proxy for the overall level of IMS. More specifically, it focuses on the integration of the quality and environmental objectives based on their priority at the strategic level, using the methodology applied in Hernandez-Vivanco et al. (2016). The importance of both the QMS and EMS were included in PITEC only from 2004 to 2007, so this study had to be limited to this period. 
The level of IMS was measured as “fully”, “partially” or “non-integrated”, so table 1 summarizes the coding procedure (Hernandez-Vivanco et al., 2016). Firms that were integrated corresponded to $79.65 \%$ of the sample. This is in good agreement with the high integration level at the strategic stage -more than 78\% in policy, objectives and planning- in most Spanish companies (Bernardo et al., 2012). As expected, the level of IMS at the strategic stage determines the overall level of IMS previously reported in Spanish firms: more than $76 \%$ in most firms described by Bernardo et al. (2009; 2012) and a minimum of 78\% according to Abad et al. (2014).

Insert Table 1 about here

\subsubsection{Measurement model of innovation efficiency}

For measuring innovation efficiency scores, the Partial Frontier Approach, namely the order- $\alpha$ input oriented method is selected (Aragon et al., 2005). This method is a generalization of the Free Disposal Hull (Deprins et al., 1984), but only assumes the input disposability of the Decision Making Units (in this case, firms). In managerial terms, this assumption means using less inputs for obtaining more outputs. Moreover, the order- $\alpha$ is less sensible to outliers compared to the Data Envelopment Analysis (Charnes et al., 1978).

Outliers are identified using different order- $\alpha(\alpha=95,96, \ldots, 100)$ (Daraio and Simar, 2007). The potential economic issue of producing (non-zero) outputs without consuming resources (Thanassoulis et al., 2008) is also solved. An intertemporal estimation is considered to get comparability between firms of the same industry over years (Mittal et al., 2005). The bootstrapping method is useful for estimating the standard errors (refer to Tauchmann (2012) for further econometrical details). The cleaning of the PITEC database is based on the former requirements, obtaining a final dataset of 570 observations. 


\subsection{Model for the comparison of innovation efficiency based on IMS and OI}

This subsection explains how $\mathrm{H} 1$ and H3a will be tested. This is, testing how innovation efficiency differs between integrated and not integrated firms (H1) and between open and closed firms (H3a).

A proxy for IMS was obtained in Table 1. To measure OI, the variable OI indicates whether firms cooperated externally between $t-2$ and $t$ for innovating (Ahn et al., 2017; Barge-Gil, 2013); its descriptive statistics are summarized in Table 2, panel A. This variable is obtained directly from the PITEC survey and equals one if firms collaborated actively with at least one source among: i) suppliers, ii) clients or customers, iii) competitors, iv) consultants and labs, v) universities or other higher education institutions, vi) public research institutes, and vii) technological centers; otherwise OI is coded as zero.

Insert Table 2 about here

The Mann-Whitney-Wilcoxon test (Mann and Whitney, 1947; Wilcoxon, 1945) will provide the likelihood of having higher innovation efficiency depending on the level of IMS and openness. The Harrell's C statistic (Newson, 2006) will be applied for estimating the probability and the confidence intervals of: i) non-integrated firms to be more efficient than fully integrated (H1), and ii) firms that perform OI to be more efficient than their counterparts (HЗа).

\subsection{Model for measuring the effects on firm performance}

In this subsection, a model for testing $\mathrm{H} 2$ and $\mathrm{H} 3 \mathrm{~b}$ is developed. This is, measuring the effect of innovation efficiency on firm performance (H2) and the moderating effect of OI in the previous relationship (H3b).

\subsubsection{Dependent variable}

The innovative sales productivity is used as a proxy for firm performance, as it is directly related to innovation efficiency through the market perspective (Wang et al., 2016). This measure reflects the productivity of the firms for transforming their innovations into 
sales, standardized in terms of their size (employees). Thus, the innovative sales productivity is a measure of the innovative sales per employee (Belderbos et al., 2004; Tsai, 2009), to represent the capacity of firms to increase their revenues through the sales of new products with the same workforce, or to realize the same amount of sales with a smaller workforce (de Leeuw et al., 2014). Equation 2 represents this measurement. Because it is a skewed variable, the natural logarithm is calculated and used, as commonly done in the existing literature (de Leeuw et al., 2014). Its descriptive statistics are shown in Table 2, panel A.

(Equation 2) Innovative sales productivity $=\ln ((\%$ of sales of new products / number of

$$
\text { employees) }+1)
$$

\subsubsection{Independent variables}

This model aims to determinate the effect of innovation efficiency on firm performance (H2), and the moderating effect of OI (H3b). The efficiency scores are taken from section 3.2. and OI is measured as a binary variable, as pointed out in section 3.3.. Table 2, panel A summarizes the dependent and explanatory variables used in this model.

\subsubsection{Control variables}

Different industries produce different innovation results (Hoang et al., 2006; Lanjouw and Schankerman, 2002). Moreover, the company size may vary IMS implementation (Zeng et al., 2007), and might present different results in terms of innovation efficiency and firm performance (Cruz-Cázares et al. 2013), so it is included as a dummy variable that equals 0 for small and medium enterprises and 1 for large. Finally, the variable Year is also considered since this is longitudinal study. Table 2, panel B summarizes the descriptive statistics of the control variables.

3.4.4. The model relating innovation efficiency, open innovation and firm performance A panel regression analysis will be used to analyze how innovation efficiency and OI are related to firm performance. The innovative sales productivity is used as a proxy of the performance. As previously shown in equation 2, its minimum value is zero when firms do 
not produce any sales from its new products, which means that data is censored or limited at this point. This characteristic can be controlled using the left-censored-Tobit approach (Tobin, 1958). The random-effect panel analysis is selected to avoid biased estimates of fixed-effects (Honore, 1992), and for obtaining conclusions about the whole population. Hence, the Censored-Tobit and non-censored panel regressions will be estimated using Stata/SE 14.0 to compare the robustness of these models. Figure 2 represents these analyses, where $\beta_{1}$ refers to $\mathrm{H} 2$ and $\beta_{2}$ to $\mathrm{H} 3 \mathrm{~b}$.

Insert Figure 2 about here

\section{Results}

The results of the efficiency scores are shown in Table 3. It is evidenced that low and medium technology firms have a slightly lower efficiency mean compared to high technology firms. Although, on average, such differences are not greatly different, they might be attributed to the fact that non-technological firms base their innovations on their creativity to transform innovation inputs into outputs rather than on science. Conversely, high technology firms are more dependent on developing their competitive advantages from an efficient process of science-based innovations to survive in more turbulent environments (Bender and Laestadius, 2005; Cruz-Cázares et al. 2013). Regarding industries, it is not surprising to find different efficiency scores even within each category. This might be mainly attributed to the fact that firms use resources and produce outputs that are mainly comparable with other firms from the same industry (Cruz-Cázares et al. 2013, Guan et al. 2006, Lee et al. 2010).

Insert Table 3 about here 
The results from the Mann-Whitney-Wilcoxon tests for H1 and H3a (Figure 3) suggest that fully integrated companies are significantly more efficient innovating (median $=1$ ) than others (median $=0.75$ ) with an associated probability of 0.67 , so H1 is supported.

Conversely, closed companies are significantly more efficient (median $=0.75)$ than open firms (median $=0.68$ ) with an associated probability of 0.55 , thus rejecting H3a.

Insert Figure 3 about here

Table 4 summarizes the results of the econometrical models represented in Figure 2. Both the Censored-Tobit (34 censored observations) and the non-censored panel regressions are robust with high rho-values, above 0.70 (Pedroni, 2004). Moreover, both regressions have a better fit compared to the constant-only model. According to the Akaike and Bayesian information criteria (AIC and BIC, respectively) the non-censored regression provides better results since both AIC and BIC statistics are higher than that of the Censored-Tobit (Raftery, 1995; Sakamoto et al., 1986). The analyses evidence that innovation efficiency positively affects firm performance in terms of innovative sales productivity, hence H2 is supported. However, even if $\sim 60 \%$ of the firms are open, OI does not moderate the previous relationship, so H3b is not supported.

Insert Table 4 about here

Regarding the control variables, results suggest that small and medium enterprises perform better compared to large companies since they devote less employees to create more innovative sales. This might be due to their market-driven rather than research-driven orientation that allows them to respond quicker to new opportunities (OECD, 1997). Industries have no significant differences of their innovative sales productivity respect to the reference (Food \& beverages), except for the software industry. Its performance is 
significantly higher, mainly because sourcing and revealing is widespread among this sector, which might force them to be more efficient than others (Caputo et al., 2016). Finally, the variable year was not significant.

Table 5 summarizes the main results of the empirically supported and non-supported hypotheses. Results suggest that fully integrated companies are more efficient innovating (H1), and this, in turn, positively affects firm performance (H2). Moreover, H3a is not supported and results are contrary to the hypothesis: companies that practice OI are found less efficient innovating. Finally, H3b is not supported since OI does not moderate the effect of innovation efficiency on firm performance. Thus, H3 is not supported.

Insert Table 5 about here

\section{Discussion}

This research is focused on IMS and OI as potential drivers of innovation efficiency to promote firm performance. In general terms, efficiency refers to the relative proficiency of firms for transforming inputs into outputs (Deprins et al., 1984). Therefore, innovation efficiency refers to the relative efficiency of firms for transforming innovation inputs (human and financial resources) into outputs (innovations) (see e.g., Cruz-Cázares et al., 2013; Wang et al., 2016). To provide robust results of this relative efficiency, an intertemporal estimation was considered to get comparability between firms of the same industry over years (Mittal et al., 2005). In this line, this research focused on innovation efficiency in the sense that firms might require fewer resources to produce more innovations than others in the same industry.

Once the innovation inputs are transformed into outputs, firms might benefit, in a second stage, of an enhanced performance through commercialization (Guan and Chen, 2010; Wang et al., 2016) and an optimized use of resources (Cruz-Cázares et al., 2013). In this second stage, this study focused on the capacity of firms for transforming their innovations into sales, standardized in terms of their employees, which is referred to as the innovation sales productivity (similarly to Arvanitis, 2012; Belderbos et al., 2004; de Leeuw et al., 2014; Tsai, 2009). 
According to the results, $\mathrm{H} 1$ is supported, suggesting that IMS drives innovation efficiency. IMS seems to facilitate the creation of links between specialists, as proposed by the knowledge-based view theory (Grant, 1996). Even if only 15.44\% of the firms were fully integrated, IMS benefits for increasing efficiency seem to go beyond the purely organizational standpoint (Nunhes et al., 2016; Simon and Douglas, 2013). IMS appears to create an accurate environment for innovating more efficiently, which could be a consequence of the increased innovation capabilities obtained from its implementation (Hernandez-Vivanco et al., 2016). Moreover, IMS promotes transparency and awareness of interdependences between the quality and environmental aspects of new developments (von Ahsen, 2014), and it has been acknowledged as a sustainability-oriented management practice (Gianni et al., 2017). Thus, since IMS might foster innovation efficiency, its benefits might be closely related to the optimization of resources through the application of the quality-related principles and the minimization of environmental impacts of innovations (Gianni et al., 2017; Nunhes et al., 2016).

Regarding the positive relationship between innovation efficiency and firm performance, results support H2. This suggests that companies that are more efficient innovating have better chances of translating that efficiency into sales productivity of new products. Wang \& Wang (2012) found a similar influence in intensity and significance when asking firms to evaluate both factors from their own perspective. This study confirms the former results and diminishes subjectivity by benchmarking (measuring efficiency) objectively, which is in line with existing literature (Cruz-Cázares et al., 2013; Guan and Chen, 2010; Wang et al., 2016).

Regarding OI, H3 is not empirically supported. Results suggest that open firms are significantly less efficient innovating than closed firms, contrary to H3a. Although the difference is significant, the probability of open firms being more efficient than closed firms is $45 \%$. Such probability, although close to being non-significant suggests that the additional inputs to perform OI results on a limited increase of innovation outputs (Cuerva et al., 2014). This might occur because OI is not costless and openness does not always lead to benefits (Caputo et al., 2016). In addition to use additional resources (Greco et al., 2016; Laursen and Salter, 2006), OI demands combining diverse types of knowledge and performing several organizational changes, which implicates big efforts that are not always compensated by 
innovation outputs (Ahn et al., 2017). This excess of resources in this stage of the innovative process might also hinder the capacity of firms to pursue sustainability (Kennedy et al., 2017; Pacheco et al., 2017). Despite these difficulties, results show a relatively small difference in innovation efficiency, which seems to be manageable through the same innovation capabilities gained from both, the OI practice itself (Cheng et al., 2016) and its interaction with IMS (Hernandez-Vivanco et al., 2016). However, this research could not determine to what extent or through which mechanisms firms could manage to harness the benefits of OI to avoid spending excessive resources along the path to produce innovation outputs (Greco et al., 2016).

Results suggest that OI does not moderate the relationship between innovation efficiency and firm performance, so H3b is not supported. As previously discussed, OI seems to decrease innovation efficiency. Thus, the lack of significance of the moderating effect of OI suggests that the innovation inefficiencies observed in open firms seem to be compensated so firm performance is not hindered. More specifically, OI might allow firms to be more effective when exploiting their innovations in the market (Chesbrough and Bogers, 2014) and to gain new innovation capabilities, which remain in their workforce (Behnam et al., 2018; Cheng et al., 2016). Therefore, even if firms might experience decreases of innovation efficiency when adopting OI, these inefficiencies might be compensated by an unaffected capacity of commercializing their new products with the same workforce, or to realize the same amount of sales with a smaller workforce (de Leeuw et al., 2014). Moreover, not supporting H3b evidences that, although there have been substantial studies relating OI and firm performance, this relationship is still not clear and further research should be performed to disentangle it (Lopes and de Carvalho, 2018).

The fact that IMS seems to be beneficial to innovation efficiency, whereas OI appears to be detrimental should be discussed in the context of the selected sample. As observed in Spanish firms, IMS is a common practice to this population (see e.g., Bernardo et al., 2009). Moreover, its interaction with OI might increase, particularly, process and product innovation capabilities (Hernandez-Vivanco et al., 2016). This advantageous situation for Spanish firms during the studied period is reflected in their generalized tendency to enhance their innovation efficiency (Cruz-Cázares et al., 2013). This trend would have been optimal to open firms for boosting their innovation efficiency, if combined with a policy that promotes 
cooperative R\&D projects (Broekel, 2015). However, Spain did not apply the right policy in that time to deal with an open trading market (among other factors) and, consequently, to favor OI according to the specialized literature (Balsalobre-Lorente et al., 2018). The lack of attention given to OI might be mainly attributed to its novelty to Spanish firms during the studied period, which led them to adopt more closed than OI strategies (Cruz-Cázares et al., 2012) and to exploit their innovations internally rather than externally (Sikimic et al., 2016). Therefore, Spanish companies might have been focused on improving their innovation efficiency through the internal optimization of their innovation activities rather than through the exploitation of OI. This might explain to some extent why, in this study, IMS is evidenced to foster innovation efficiency, while OI appears to be negatively related to it.

\section{Conclusions}

In this study, the integration of management systems and open innovation are studied as two managerial drivers of innovation efficiency in pursuit of improving their performance. Using a sample of 220 Spanish companies, results suggest that IMS facilitates the enhancement of innovation efficiency while OI might provide some manageable inefficiency. Moreover, innovation efficiency allows firms to perform better in terms of the productivity in the sales of new products.

This research has three main implications for the academia. Firstly, this paper measures IMS by minimizing subjectivity, as firms were not asked to assess directly their level of IMS. According to the results, IMS might be a relevant driver of innovation efficiency due to alignment of goals (Bernardo et al., 2009; Nunhes et al., 2017; Salomone, 2008) and the optimization of the human and financial resources (Abad et al., 2014;

Salomone, 2008; Santos et al., 2011). Secondly, innovation efficiency means optimizing resources when producing innovation outputs, which, in turn, promote firm performance. Hence, the efforts invested in innovation seem to pay off through the optimization of resources that, consequently, benefits firms in terms of their productivity when commercializing their new products. Finally, this study evidences empirically the need of further researching into the role of OI and IMS to promote sustainable development and avoid the excessive use of resources in this process (Kennedy et al., 2017; Pacheco et al., 2017). 
The managerial implications of this study are mainly three. Firstly, companies that apply multiple MS (not necessarily certified) might consider IMS benefits beyond the purely operational (Nunhes et al., 2016; Simon and Douglas, 2013), since IMS might also benefit innovation efficiency and, ultimately, contribute to firm performance. Secondly, firms are challenged to seek the right level of openness to exploit the external knowledge of practicing OI without hindering their innovation efficiency. OI and IMS are two complementary and synergic managerial practices (Hernandez-Vivanco et al., 2016) that involve different stakeholders and improve together innovation capabilities (Behnam et al., 2018). In this sense, companies might see OI as a way to exploit external knowledge in order to favor the internal support provided by IMS to innovate. However, companies ought to be cautious when investing in an OI strategy, especially when the efforts invested on external collaborations are not producing significant additional innovation outputs. Finally, although results suggest that OI might hinder innovation efficiency, it is also remarked that such differences are manageable, so firms should seek for efficient sources of knowledge and exploit the advantages of the resulting knowledge and capabilities. To this end, IMS might provide the internal support to open firms in order to harness external knowledge. By creating synergies between the internal and external knowledge, innovation collaborators might be able to benefit not only of added innovation efficiency (Greco et al., 2017), but also of their conjoint sustainable growth (Watson et al., 2018).

The main implication to policy makers lays on the importance that should be given to promote innovation through the improvement of both internal and collaborative practices. This research has evidenced that, during the studied period, Spanish firms seemed to attach substantially more importance to their internal performance (IMS) rather than to harness the benefits of OI. This has been mainly attributed to the traditional approach of Spanish firms to adopt several MSs (ISO, 2017) and IMS (Bernardo et al., 2009), as opposed to the lack of governmental support towards collaborative innovation practices during the studied period (Balsalobre-Lorente et al., 2018). Policy makers might consider that both IMS and OI are compatible (Hernandez-Vivanco et al., 2016) and both might have a major role towards sustainable development (Gianni et al., 2017; Kennedy et al., 2017; Nunhes et al., 2016; Pacheco et al., 2017). Thus, promoting these practices in a balanced and constructive fashion might be beneficial to society in terms of innovation and sustainability. 
Regarding the contribution of this work, this is one of the first studies finding empirical evidence of two managerial practices seeking to foster innovation efficiency: OI and IMS. It also contributes to the literature focused on innovation efficiency by considering product, process and organizational innovations. Finally, this research sheds light on understanding how innovation efficiency might benefit firm performance when OI and IMS are implemented.

Despite the contributions of this study, it is not absent of limitations. Firstly, using a secondary database limited this study to the available information, so it was not possible to consider: i) other MSs (e.g., Accounting Sustainability, Operational Health and Safety, among others), ii) other important aspects related to sustainability, and iii) extend the study to more recent observations (similarly to de Leeuw et al., 2014; Sikimic et al., 2016). The latter limitation was due to the anonymized nature of the microdata that restricted this study to the availability of indicators in the studied dataset. Secondly, even if measuring the variables of this study minimized subjectivity, some proxies had to be used based on the existing literature. Finally, the studied sample comprised only Spanish firms, so these conclusions might not be representative of other populations in which MSs have not been widely implemented.

Future research will be focused on analyzing the role of OI and IMS towards innovation efficiency when firms are exposed to diverse policies over a long time-span, which might lead to dynamic changes in innovation efficiency. Further research should also focus on the mechanisms to promote sustainability-oriented innovations when firms adopt IMS and OI. Finally, further studies might analyze differences across sectors and countries.

\section{References}

Abad, J., Dalmau, I., Vilajosana, J., 2014. Taxonomic proposal for integration levels of management systems based on empirical evidence and derived corporate benefits. J. Clean. Prod. 78, 164-173. doi:10.1016/j.jclepro.2014.04.084

Acs, Z.J., Anselin, L., Varga, A., 2002. Patents and innovation counts as measures of regional production of new knowledge. Res. Policy 31, 1069-1085. doi:10.1016/S00487333(01)00184-6

Ahn, J.M., Minshall, T., Mortara, L., 2017. Understanding the human side of openness: the 
fit between open innovation modes and CEO characteristics. R\&D Manag. 47, 727740. doi:10.1111/radm.12264

Aragon, Y., Daouia, A., Thomas-Agnan, C., 2005. Nonparametric Frontier Estimation: a Conditional Quantile-Based Approach. Econom. Theory 21, 358-389. doi:10.1017/S0266466605050206

Arvanitis, S., 2012. How do different motives for R\&D cooperation affect firm performance? - An analysis based on Swiss micro data. J. Evol. Econ. 22, 981-1007. doi:10.1007/s00191-012-0273-5

Balsalobre-Lorente, D., Shahbaz, M., Roubaud, D., Farhani, S., 2018. How economic growth, renewable electricity and natural resources contribute to CO 2 emissions? Energy Policy 113, 356-367. doi:10.1016/j.enpol.2017.10.050

Barge-Gil, A., 2013. Open Strategies and Innovation Performance. Ind. Innov. 20, 585-610. doi:10.1080/13662716.2013.849455

Behnam, S., Cagliano, R., Grijalvo, M., 2018. How should firms reconcile their open innovation capabilities for incorporating external actors in innovations aimed at sustainable development? J. Clean. Prod. 170, 950-965. doi:10.1016/j.jclepro.2017.09.168

Belderbos, R., Carree, M., Lokshin, B., 2004. Cooperative R\&D and firm performance. Res. Policy 33, 1477-1492. doi:10.1016/j.respol.2004.07.003

Bernardo, M., 2014. Integration of management systems as an innovation: a proposal for a new model. J. Clean. Prod. 82, 132-142. doi:10.1016/j.jclepro.2014.06.089

Bernardo, M., Casadesus, M., Karapetrovic, S., Heras, I., 2012. Integration of standardized management systems: does the implementation order matter? Int. J. Oper. Prod. Manag. 32, 291-307. doi:10.1108/01443571211212583

Bernardo, M., Casadesus, M., Karapetrovic, S., Heras, I., 2009. How integrated are environmental, quality and other standardized management systems? An empirical study. J. Clean. Prod. 17, 742-750. doi:10.1016/j.jclepro.2008.11.003

Broekel, T., 2015. Do Cooperative Research and Development (R\&D) Subsidies Stimulate Regional Innovation Efficiency? Evidence from Germany. Reg. Stud. 49, 1087-1110. doi:10.1080/00343404.2013.812781

Caputo, M., Lamberti, E., Cammarano, A., Michelino, F., 2016. Exploring the impact of open 
innovation on firm performances. Manag. Decis. 54, 1788-1812. doi:10.1108/MD-022015-0052

Charnes, A., Cooper, W.W., Rhodes, E., 1978. Measuring the efficiency of decision making units. Eur. J. Oper. Res. 2, 429-444. doi:10.1016/0377-2217(78)90138-8

Cheng, C.C.J., Yang, C., Sheu, C., 2016. Effects of open innovation and knowledge-based dynamic capabilities on radical innovation: An empirical study. J. Eng. Technol. Manag. 41, 79-91. doi:10.1016/j.jengtecman.2016.07.002

Chesbrough, H., Bogers, M., 2014. Explicating Open Innovation: Clarifying an Emerging Paradigm for Understanding Innovation Keywords, in: Chesbrough, H., Vanhaverbeke, W., West, J. (Eds.), New Frontiers in Open Innovation. Oxford University Press, Oxford, England, pp. 3-28.

Chesbrough, H.W., 2007. Why Companies Should Have Open Business Models. MIT Sloan Manag. Rev. 48, 22-28.

Chesbrough, H.W., 2003. Open innovation: The new imperative for creating and profiting from technology, Harvard Business School Press. Boston, MA.

Cruz-Cázares, C., Bayona-Sáez, C., García-Marco, T., 2013. You can’t manage right what you can’t measure well: Technological innovation efficiency. Res. Policy 42, 1239_ 1250. doi:10.1016/j.respol.2013.03.012

Cruz-Cázares, C., Smits, A., Berends, H., Reymen, I., Anzola, P., Bayona-Sáez, C., GarcíaMarco, T., Schubert, M., Sturm, F., 2012. BMOI Report - A Regional Comparison of Open Innovation Practices. The Netherlands.

Cuerva, M.C., Triguero-Cano, Á., Córcoles, D., 2014. Drivers of green and non-green innovation: Empirical evidence in Low-Tech SMEs. J. Clean. Prod. 68, 104-113. doi:10.1016/j.jclepro.2013.10.049

Daraio, C., Simar, L., 2007. Advanced Robust and nonparametric methods in efficiency analysis: methodology and applications. Springer Science \& Business Media.

de Leeuw, T., Lokshin, B., Duysters, G., 2014. Returns to alliance portfolio diversity: The relative effects of partner diversity on firm's innovative performance and productivity. J. Bus. Res. 67, 1839-1849. doi:10.1016/j.jbusres.2013.12.005

Deprins, D., Simar, L., Tulekns, H., 1984. Measuring laborefficiency in post office, in: Marchand, M., Pestieau, P., Tulkens, H. (Eds.), The Performance of Public Enterprises: 
Concepts and Measurement. Amsterdam: North-Holland, pp. 243-268. doi:10.1007/b135529

Drivas, K., Economidou, C., Tsionas, E.G., 2018. Production of output and ideas: efficiency and growth patterns in the United States. Reg. Stud. 52, 105-118. doi:10.1080/00343404.2016.1275536

Fichman, R.G., 2004. Going Beyond the Dominant Paradigm for Information Technology Innovation Research: Emerging Concepts. J. Assoc. Inf. Syst. 5, 314-355.

Garechana, G., Río-Belver, R., Bildosola, I., Salvador, M.R., 2017. Effects of innovation management system standardization on firms: evidence from text mining annual reports. Scientometrics 111, 1987-1999. doi:10.1007/s11192-017-2345-7

Gavronski, I., Klassen, R.D., Vachon, S., Machado do Nascimento, L.F., 2012. A learning and knowledge approach to sustainable operations. Int. J. Prod. Econ. 140, 183-192. doi:10.1016/j.ijpe.2012.01.037

George, G., Zahra, S.A., Wood, D.R., 2002. The effects of business-university alliances on innovative output and financial performance: a study of publicly traded biotechnology companies. J. Bus. Ventur. 17, 577-609. doi:10.1016/S0883-9026(01)00069-6

Geum, Y., Kim, J., Son, C., Park, Y., 2013. Development of dual technology roadmap (TRM) for open innovation: Structure and typology. J. Eng. Technol. Manag. - JET-M 30, 309325. doi:10.1016/j.jengtecman.2013.06.001

Gianni, M., Gotzamani, K., Tsiotras, G., 2017. Multiple perspectives on integrated management systems and corporate sustainability performance. J. Clean. Prod. 168, 1297-1311. doi:10.1016/j.jclepro.2017.09.061

Grant, R.M., 1996. Toward a Knowledge-Based Theory of the Firm. Strateg. Manag. J. 17, $109-122$.

Greco, M., Grimaldi, M., Cricelli, L., 2017. Hitting the nail on the head: Exploring the relationship between public subsidies and open innovation efficiency. Technol. Forecast. Soc. Change 118, 213-225. doi:10.1016/j.techfore.2017.02.022

Greco, M., Grimaldi, M., Cricelli, L., 2016. An analysis of the open innovation effect on firm performance. Eur. Manag. J. 34, 501-516. doi:10.1016/j.emj.2016.02.008

Griliches, Z., 1990. Patent Statistics as Economic Indicators: A Survey. J. Econ. Lit. 28, 1661-1707. doi:10.3386/w3301 
Guan, J., Chen, K., 2010. Measuring the innovation production process: A cross-region empirical study of China's high-tech innovations. Technovation 30, 348-358. doi:10.1016/j.technovation.2010.02.001

Guan, J., He, Y., 2007. Patent-bibliometric analysis on the Chinese science - Technology linkages. Scientometrics 72, 403-425. doi:10.1007/s11192-007-1741-1

Guan, J., Yam, R.C.M., Mok, C.K., Ma, N., 2006. A study of the relationship between competitiveness and technological innovation capability based on DEA models. Eur. J. Oper. Res. 170, 971-986. doi:10.1016/j.ejor.2004.07.054

Guan, J., Zuo, K., Chen, K., Yam, R.C.M., 2016. Does country-level R\&D efficiency benefit from the collaboration network structure? Res. Policy 45, 770-784. doi:10.1016/j.respol.2016.01.003

Hashimoto, A., Haneda, S., 2008. Measuring the change in R\&D efficiency of the Japanese pharmaceutical industry. Res. Policy 37, 1829-1836. doi:10.1016/j.respol.2008.08.004

Hernandez-Vivanco, A., Bernardo, M., Cruz-Cázares, C., 2016. Relating open innovation, innovation and management systems integration. Ind. Manag. Data Syst. 116, 15401556. doi:10.1108/IMDS-09-2015-0405

Hoang, D.T., Igel, B., Laosirihongthong, T., 2006. The impact of total quality management on innovation: Findings from a developing country. Int. J. Qual. Reliab. Manag. 23, 1092-1117. doi:10.1108/02656710610704230

Honore, B.Y.B.E., 1992. Trimmed Lad and Least Squares Estimation of Truncated and Censored Regression Models with Fixed Effects. Econometrica 60, 533-565.

ISO, 2018. aManagement system standards [WWW Document]. URL https://www.iso.org/management-system-standards.html (accessed 2.15.18).

ISO, 2017. The ISO Survey of Certifications. International Organization for Standardization, Geneva, Switzerland.

Jørgensen, T.H., Remmen, A., Mellado, M.D., 2006. Integrated management systems - Three different levels of integration. J. Clean. Prod. 14, 713-722. doi:10.1016/j.jclepro.2005.04.005

Karapetrovic, S., 2003. Musings on integrated management systems. Meas. Bus. Excell. 7, 4-13. doi:10.1108/13683040310466681

Kennedy, S., Whiteman, G., van den Ende, J., 2017. Radical Innovation for Sustainability: 
The Power of Strategy and Open Innovation. Long Range Plann. 50, 712-725. doi:10.1016/j.lrp.2016.05.004

Kim, D.-Y., Kumar, V., Kumar, U., 2012. Relationship between quality management practices and innovation. J. Oper. Manag. 30, 295-315. doi:10.1016/j.jom.2012.02.003

Klepper, S., 1996. Entry, exit, growth, and innovation over the product life cycle. Am. Econ. Rev. 86, 562-583.

Klomp, L., Van Leeuwen, G., 2001. Linking Innovation and Firm Performance: A New Approach. Int. J. Econ. Bus. 8, 343-364. doi:10.1080/13571510110079612

Koellinger, P., 2008. The relationship between technology, innovation, and firm performance-Empirical evidence from e-business in Europe. Res. Policy 37, 13171328. doi:10.1016/j.respol.2008.04.024

Lanjouw, J.O., Schankerman, M., 2002. Research productivity and patent quality: measurement with multiple indicators. Econ. J. 114, 441-465.

Laursen, K., Salter, A., 2006. Open for innovation: The role of openness in explaining innovation performance among U.K. manufacturing firms. Strateg. Manag. J. 27, 131150. doi:10.1002/smj.507

Lee, S.K., Mogi, G., Lee, S.K., Hui, K.S., Kim, J.W., 2010. Econometric analysis of the R\&D performance in the national hydrogen energy technology development for measuring relative efficiency: The fuzzy AHP/DEA integrated model approach. Int. J. Hydrogen Energy 35, 2236-2246. doi:10.1016/j.ijhydene.2010.01.009

Liu, Z., Chen, X., Chu, J., Zhu, Q., 2017. Industrial development environment and innovation efficiency of high-tech industry: analysis based on the framework of innovation systems. Technol. Anal. Strateg. Manag. 1-13. doi:10.1080/09537325.2017.1337092

Lopes, A.P.V.B.V., de Carvalho, M.M., 2018. Evolution of the open innovation paradigm: Towards a contingent conceptual model. Technol. Forecast. Soc. Change 132, 284-298. doi:10.1016/j.techfore.2018.02.014

Mann, H.B., Whitney, D.R., 1947. On a Test of Whether one of Two Random Variables is Stochastically Larger than the Other. Ann. Math. Stat. 18, 50-60.

Matias, J.C.D.O., Coelho, D.A., 2011. Integrated total quality management: Beyond zero defects theory and towards innovation. Total Qual. Manag. Bus. Excell. 22, 891-910. doi:10.1080/14783363.2011.593862 
Mir, M., Casadesús, M., Petnji, L.H., 2016. The impact of standardized innovation management systems on innovation capability and business performance: An empirical study. J. Eng. Technol. Manag. 41, 26-44. doi:10.1016/j.jengtecman.2016.06.002

Mittal, V., Anderson, E.W., Sayrak, A., Tadikamalla, P., 2005. Dual Emphasis and the LongTerm Financial Impact of Customer Satisfaction. Mark. Sci. 24, 544-555. doi:10.1287/mksc.1050.0142

Moreno-Luzon, M.D., Gil-Marques, M., Valls-Pasola, J., 2013. TQM, innovation and the role of cultural change. Ind. Manag. Data Syst. 113, 1149-1168. doi:10.1108/imds-022013-0075

Newson, R., 2006. Confidence intervals for rank statistics: Somers’ D and extensions. Stata J. 6, 309-334.

Nunhes, T.V., Ferreira Motta, L.C., de Oliveira, O.J., 2016. Evolution of integrated management systems research on the Journal of Cleaner Production: Identification of contributions and gaps in the literature. J. Clean. Prod. 139, 1234-1244. doi:10.1016/j.jclepro.2016.08.159

Nunhes, T.V., Motta Barbosa, L.C.F., de Oliveira, O.J., 2017. Identification and analysis of the elements and functions integrable in integrated management systems. J. Clean. Prod. 142, 3225-3235. doi:10.1016/j.jclepro.2016.10.147

OECD, 2008. Open Innovation in Global Networks.

OECD, 2005. Oslo Manual: Guidelines for Collecting and Interpreting Innovation Data, 3rd Edition, The Measurement of Scientific and Technological Activities. OECD Publishing. doi:10.1787/9789264013100-en

OECD, 1997. Small businesses, job creation and growth: facts, obstacles and best practices. Paris.

Pacheco, D.A. de J., ten Caten, C.S., Jung, C.F., Ribeiro, J.L.D., Navas, H.V.G., CruzMachado, V.A., 2017. Eco-innovation determinants in manufacturing SMEs: Systematic review and research directions. J. Clean. Prod. 142, 2277-2287. doi:10.1016/j.jclepro.2016.11.049

Palm, K., Lilja, J., Wiklund, H., 2016. The challenge of integrating innovation and quality management practice. Total Qual. Manag. Bus. Excell. 27, 34-47. doi:10.1080/14783363.2014.939841 
Pedroni, P., 2004. Panel Cointegration: Asymptotic and Finite Sample Properties of Pooled Time Series Tests with an Application to the PPP Hypothesis. Econom. Theory 20, 597625. doi:10.1017/S0266466604203073

Perdomo-Ortiz, J., González-Benito, J., Galende, J., 2006. Total quality management as a forerunner of business innovation capability. Technovation 26, 1170-1185. doi:10.1016/j.technovation.2005.09.008

Plambeck, E.L., Taylor, T.A., 2005. Sell the Plant? The Impact of Contract Manufacturing on Innovation, Capacity, and Profitability. Manage. Sci. 51, 133-150. doi:10.1287/mnsc.1040.0212

Prajogo, D., Tang, A.K.Y., Lai, K.-H., 2014. The diffusion of environmental management system and its effect on environmental management practices. Int. J. Oper. Prod. Manag. 34, 565-585. doi:10.1108/IJOPM-10-2012-0448

Prajogo, D.I., Sohal, A.S., 2004. The multidimensionality of TQM practices in determining quality and innovation performance - An empirical examination. Technovation 24, 443453. doi:10.1016/S0166-4972(02)00122-0

Prajogo, D.I., Sohal, A.S., 2001. TQM and innovation: a literature review and research framework. Technovation 21, 539-558. doi:10.1016/S0166-4972(00)00070-5

Radonjič, G., Tominc, P., 2006. The impact and significance of ISO 14001 certification on the adoption of new technologies. Manag. Environ. Qual. An Int. J. 17, 707-727. doi:10.1108/14777830610702539

Raftery, A.E., 1995. Bayesian Model Selection in Social Research, in: Marsden, V.P. (Ed.), Sociological Methodology. Blackwell, Oxford, pp. 111-163.

Renzi, M.F., Cappelli, L., 2000. Itegration between ISO 9000 and ISO 14000: Opportunities and limits. Total Qual. Manag. 11, 849-856. doi:10.1080/09544120050008318

Romer, P., 1991. Endogenous technological change. J. Polit. Econ. 98, S71-S102.

Sakamoto, Y., Ishiguro, M., Kitagawa, G., 1986. Akaike Information Criterion Statistics. Reidel, Dordrecht, The Netherlands.

Salomone, R., 2008. Integrated management systems: experiences in Italian organizations. J. Clean. Prod. 16, 1786-1806. doi:10.1016/j.jclepro.2007.12.003

Santos, G., Mendes, F., Barbosa, J., 2011. Certification and integration of management systems: The experience of Portuguese small and medium enterprises. J. Clean. Prod. 
19, 1965-1974. doi:10.1016/j.jclepro.2011.06.017

Sikimic, U., Chiesa, V., Frattini, F., Scalera, V.G., 2016. Investigating the Influence of Technology Inflows on Technology Outflows in Open Innovation Processes: A Longitudinal Analysis. J. Prod. Innov. Manag. 33, 652-669. doi:10.1111/jpim.12319

Simon, A., Douglas, A., 2013. Integrating management systems: does the location matter? Int. J. Qual. Reliab. Manag. 30, 675-689. doi:10.1108/02656711311325629

Simon, A., Petnji Yaya, L.H., Karapetrovic, S., Casadesus, M., 2014. Can integration difficulties affect innovation and satisfaction? Ind. Manag. Data Syst. 114, 183-202. doi:10.1108/IMDS-03-2013-0148

Tauchmann, H., 2012. Partial frontier efficiency analysis. Stata J. 12, 461-478.

Thanassoulis, E., Portela, M.C.S., Despic, O., 2008. DEA—the mathematical programming approach to efficiency analysis, in: Fried, H., Lovell, C.A.K., S. Schmidt, S. (Eds.), The Measurement of Productive Efficiency and Productivity Growth. Oxford University Press, New York, NY, pp. 251-420.

Tidd, J., Bessant, J., 2009. Managing innovation; integrating technological, market and organizational change, 4th ed. ed. John Wiley \& Sons Ltd., Chichester, England.

Tobin, J., 1958. Estimation of Relationships for Limited Dependent Variables. Econometrica 26, 24-36. doi:10.2307/1907382

Tsai, K.-H., 2009. Collaborative networks and product innovation performance: Toward a contingency perspective. Res. Policy 38, 765-778. doi:10.1016/j.respol.2008.12.012

von Ahsen, A., 2014. The Integration of Quality, Environmental and Health and Safety Management by Car Manufacturers - a Long-Term Empirical Study. Bus. Strateg. Environ. 23, 395-416. doi:10.1002/bse.1791

Wagner, M., 2008. Empirical influence of environmental management on innovation: Evidence from Europe. Ecol. Econ. 66, 392-402. doi:10.1016/j.ecolecon.2007.10.001

Wagner, M., 2007. On the relationship between environmental management, environmental innovation and patenting: Evidence from German manufacturing firms. Res. Policy 36, 1587-1602. doi:10.1016/j.respol.2007.08.004

Wang, Q., Hang, Y., Sun, L., Zhao, Z., 2016. Two-stage innovation efficiency of new energy enterprises in China: A non-radial DEA approach. Technol. Forecast. Soc. Change 112, 254-261. doi:10.1016/j.techfore.2016.04.019 
Wang, Z., Wang, N., 2012. Knowledge sharing, innovation and firm performance. Expert Syst. Appl. 39, 8899-8908. doi:10.1016/j.eswa.2012.02.017

Watson, R., Wilson, H.N., Smart, P., Macdonald, E.K., 2018. Harnessing Difference: A Capability-Based Framework for Stakeholder Engagement in Environmental Innovation. J. Prod. Innov. Manag. 35, 254-279. doi:10.1111/jpim.12394

Weerawardena, J., O’Cass, A., Julian, C., 2006. Does industry matter? Examining the role of industry structure and organizational learning in innovation and brand performance. $\mathrm{J}$. Bus. Res. 59, 37-45. doi:10.1016/j.jbusres.2005.02.004

West, A.M., Anderson, R.N., 1996. Innovation in Top Management Teams. J. Appl. Psychol. 81, 680-693. doi:10.1037//0021-9010.81.6.680

Wilcoxon, F., 1945. Individual Comparisons by Ranking Methods. Int. Biometric Soc. 1, 8083.

Wong, A., Tjosvold, D., Liu, C., 2009. Innovation by teams in Shanghai, China: Cooperative goals for group confidence and persistence. Br. J. Manag. 20, 238-251. doi:10.1111/j.1467-8551.2008.00563.x

Zeng, S.X., Shi, J.J., Lou, G.X.X., 2007. A synergetic model for implementing an integrated management system: an empirical study in China. J. Clean. Prod. 15, 1760-1767. doi:10.1016/j.jclepro.2006.03.007

Ziegler, A., Seijas Nogareda, J., 2009. Environmental management systems and technological environmental innovations: Exploring the causal relationship. Res. Policy 38, 885-893. doi:10.1016/j.respol.2009.01.020 


\section{Figures}

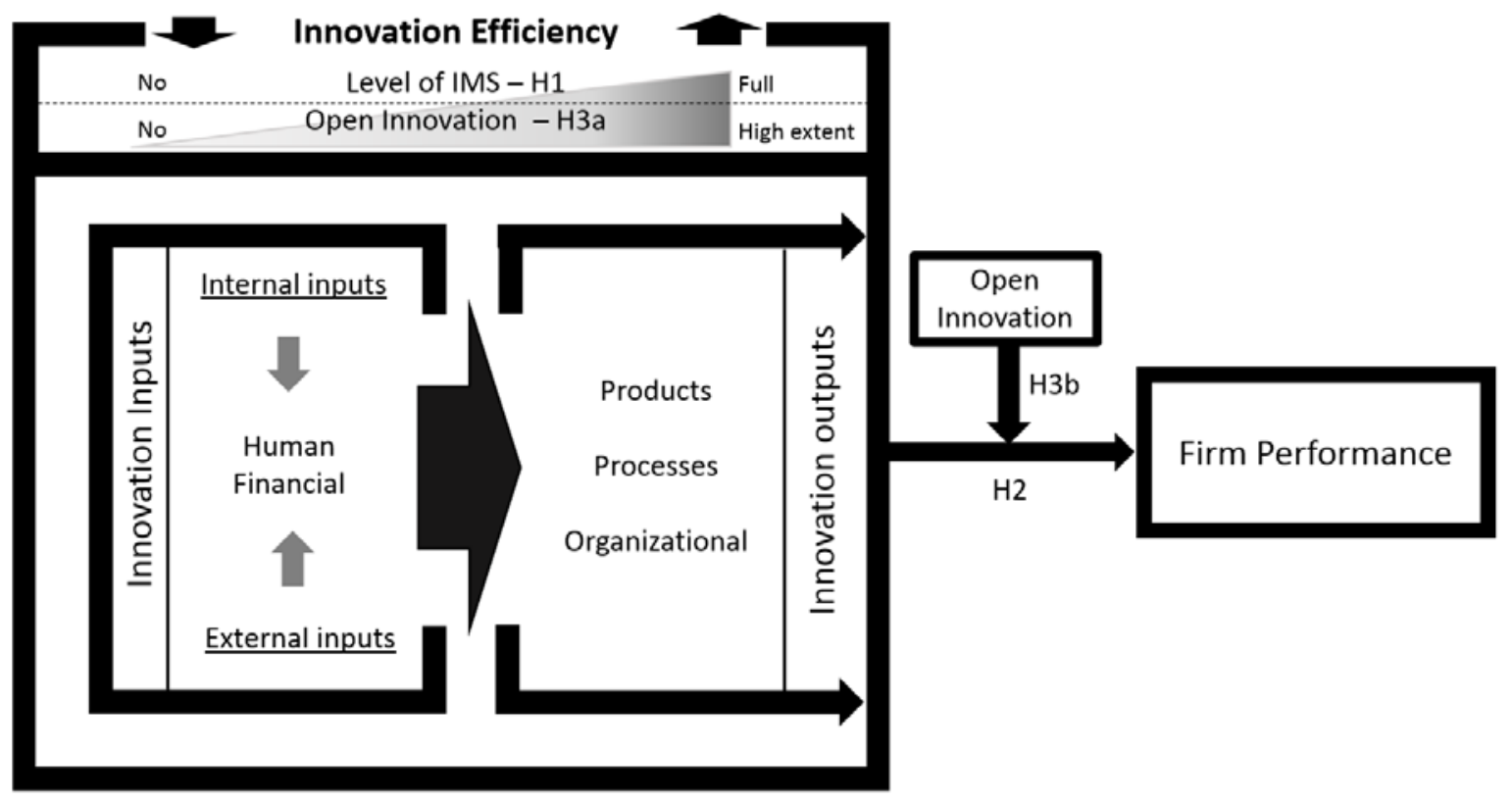

Figure 1. Model relating the integration of management systems, innovation efficiency, open innovation and firm performance

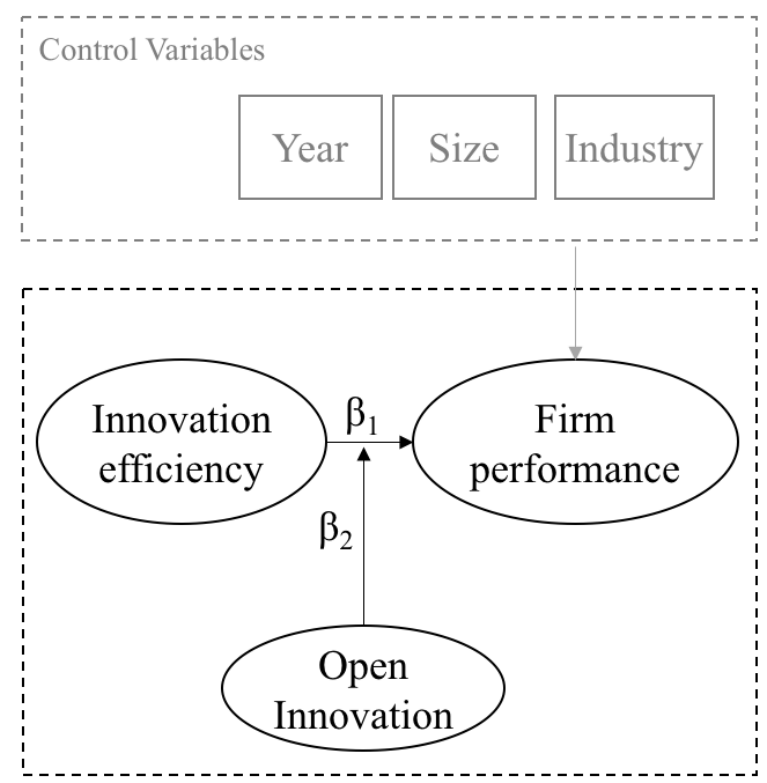

Figure 2. Panel regression and Censored-Tobit representation 


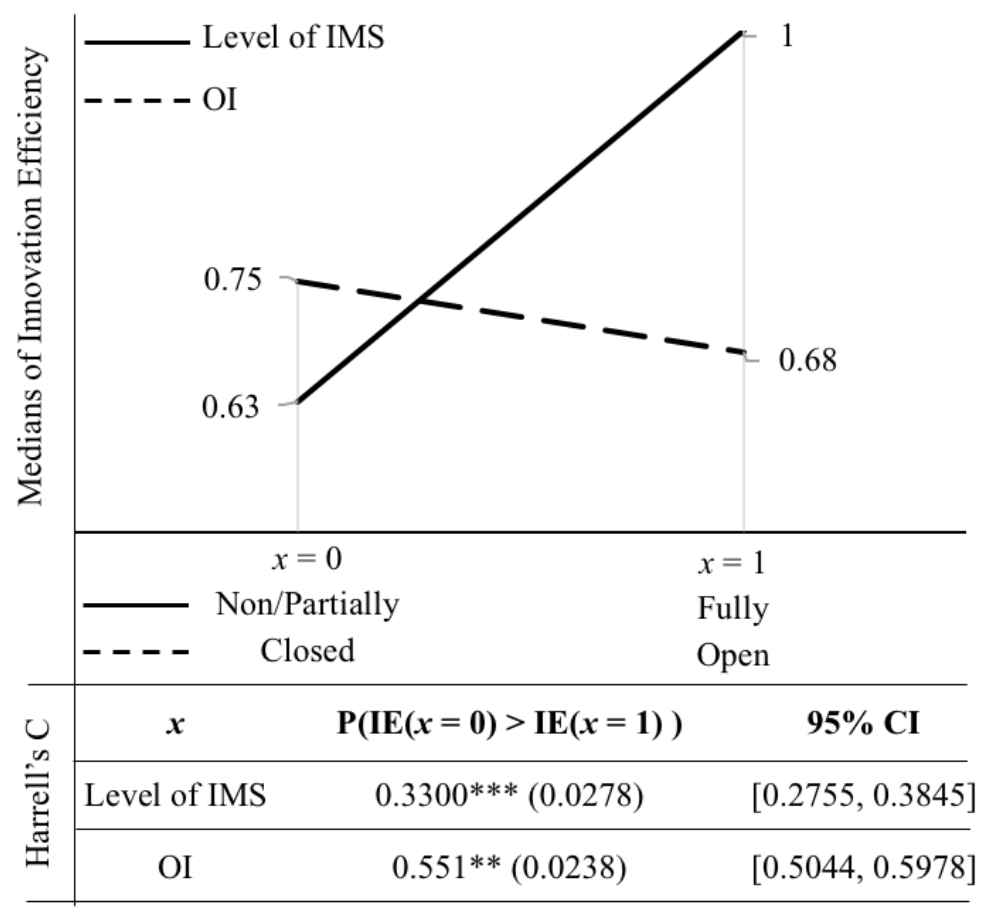

p-value for the Mann-Whitney-Wilcoxon test: ${ }^{* *} \mathrm{p}<0.05$, ${ }^{* * *} \mathrm{p}<0.01$.

The $\mathrm{H}_{0}$ is that the efficiency is the same i) at any level of IMS and ii) for closed and open firms.

Figure 3. Test of medians for comparing the innovation efficiency based on the level of IMS and OI. 


\section{$\underline{\text { Tables }}$}

Table 1. Measurement of IMS

\begin{tabular}{|c|c|c|c|c|}
\hline $\begin{array}{l}\text { Score of QMS and EMS } \\
\text { indicators }\end{array}$ & Level of IMS & Codification & Frequency & $\%$ \\
\hline Highest score for QMS and EMS & Fully integrated & 3 & 88 & 15.44 \\
\hline $\begin{array}{l}\text { Both are relevant and employed, } \\
\text { but not having the highest score at } \\
\text { least for one of the MS }\end{array}$ & $\begin{array}{c}\text { Partially } \\
\text { integrated }\end{array}$ & 2 & 366 & 64.21 \\
\hline $\begin{array}{l}\text { Not relevant or not employed at } \\
\text { least for one MS }\end{array}$ & Non-integrated & 1 & 116 & 20.35 \\
\hline
\end{tabular}


Table 2. Descriptive statistics of the panel regressions variables. Panel A shows independent and dependent variables and Panel B the control variables.

\begin{tabular}{lccccc}
\hline PANEL A. INDEPENDENT AND DEPENDENT VARIABLES & \\
\hline $\begin{array}{l}\text { Continuous } \\
\text { Variables }\end{array}$ & Mean & Std.Dev. & Min & Max & Proxy for \\
\hline $\begin{array}{l}\text { Innovative sales } \\
\text { productivity }\end{array}$ & 0.3585 & 0.5195 & 0 & 3.0445 & Firm Performance \\
\hline $\begin{array}{l}\text { Innovation Efficiency } \\
\text { scores }\end{array}$ & 0.6576 & 0.3313 & 0.0193 & 1 & Innovation Efficiency \\
\hline \multicolumn{1}{c}{ Dummy Variable } & Codification Frequency & $\%$ & & Proxy for \\
\hline $\begin{array}{l}\text { OI between } t-2 \text { and } t \\
\quad \text { Closed }\end{array}$ & 0 & 233 & 39.12 & & Open Innovation \\
$\quad$ Open & 1 & 347 & 60.88 & & \\
\hline
\end{tabular}

PANEL B. CONTROL VARIABLES

\begin{tabular}{lccc}
\hline \multicolumn{1}{c}{ Dummy Variable } & Codification Frequency & $\%$ \\
\hline Industry & & & \\
Food\&beverages & 0 & 42 & 7.37 \\
Chemical & 1 & 53 & 9.30 \\
Pharmaceutical & 2 & 45 & 7.89 \\
Rubber \& plastics & 3 & 28 & 4.91 \\
Metal & 4 & 54 & 9.47 \\
Machinery & 5 & 112 & 19.65 \\
Electrical equip. & 6 & 54 & 9.47 \\
Medical tools & 7 & 46 & 8.07 \\
Motor vehicles & 8 & 17 & 2.98 \\
Commerce & 9 & 28 & 4.91 \\
Software & 10 & 14 & 2.46 \\
R\&D & 11 & 63 & 11.05 \\
Architecture & 12 & 14 & 2.46 \\
\hline Size & & & \\
Small and medium & 0 & 398 & 69.82 \\
Large & 1 & 172 & 30.18 \\
\hline Year & & & \\
2005 & 2005 & 158 & 27.72 \\
2006 & 2006 & 220 & 38.60 \\
2007 & 2007 & 192 & 33.68 \\
\hline
\end{tabular}


Table 3. Innovation Efficiency Scores

\begin{tabular}{lccccc}
\hline Industry & Obs & Mean & Std. Dev. & Min & Max \\
\hline $\begin{array}{l}\text { Low and medium } \\
\text { technology }\end{array}$ & $\mathbf{1 6 6}$ & $\mathbf{0 . 7 0 4 0}$ & $\mathbf{0 . 3 2 3 6}$ & $\mathbf{0 . 0 5 7 1}$ & $\mathbf{1}$ \\
\hline Food \& beverages & 42 & 0.7742 & 0.3017 & 0.1154 & 1 \\
$\quad$ Rubber \& plastics & 28 & 0.7681 & 0.3251 & 0.0827 & 1 \\
Metal & 54 & 0.6181 & 0.3193 & 0.0571 & 1 \\
Commerce & 28 & 0.5871 & 0.3431 & 0.1429 & 1 \\
Architecture & 14 & 0.9303 & 0.1498 & 0.5276 & 1 \\
\hline High Technology & $\mathbf{4 0 4}$ & $\mathbf{0 . 6 3 8 5}$ & $\mathbf{0 . 3 3 3 0}$ & $\mathbf{0 . 0 1 9 3}$ & $\mathbf{1}$ \\
\hline Chemical & 53 & 0.5227 & 0.3582 & 0.0361 & 1 \\
Pharmaceutical & 45 & 0.8361 & 0.2396 & 0.2857 & 1 \\
Machinery & 112 & 0.6071 & 0.3439 & 0.0542 & 1 \\
Electrical equipment & 54 & 0.6153 & 0.3366 & 0.0958 & 1 \\
Medical tools & 46 & 0.6666 & 0.2956 & 0.0494 & 1 \\
Motor vehicles & 17 & 0.6919 & 0.4217 & 0.0193 & 1 \\
Software & 14 & 0.6337 & 0.3269 & 0.1854 & 1 \\
R\&D & 63 & 0.6369 & 0.2978 & 0.0995 & 1 \\
\hline Total & $\mathbf{5 7 0}$ & $\mathbf{0 . 6 5 7 6}$ & $\mathbf{0 . 3 3 1 3}$ & $\mathbf{0 . 0 1 9 3}$ & $\mathbf{1}$ \\
\hline
\end{tabular}


Table 4. Panel Censored-Tobit and non-censored regressions' results ( $\mathrm{N}=570)$

\begin{tabular}{lcc}
\cline { 2 - 3 } Variables & \multicolumn{2}{c}{ Firm Performance } \\
\hline & $\begin{array}{c}\text { Panel Censored- } \\
\text { Tobit }\end{array}$ & $\begin{array}{c}\text { Panel Non- } \\
\text { Censored } \\
\text { Regression }\end{array}$ \\
\hline Innovation efficiency & $0.152^{*}(0.0788)$ & $0.159^{* *}(0.0754)$ \\
\hline (Innovation efficiency) x (OI) & $-0.099(0.0629)$ & $-0.097(0.0599)$ \\
\hline Size & $-0.294^{* * *}(0.070)$ & $-0.310^{* * *}(0.0668)$ \\
\hline 1.Large & $0.029(0.028)$ & $0.028(0.027)$ \\
\hline Year & $0.002(0.029)$ & $0.003(0.028)$ \\
2006 & & \\
2007 & $0.111(0.139)$ & $0.112(0.112)$ \\
\hline Industry & $-0.045(0.148)$ & $-0.043(0.141)$ \\
1.Chemical & $-0.137(0.145)$ & $-0.133(0.139)$ \\
2.Pharmaceutical & $-0.010(0.144)$ & $-0.007(0.138)$ \\
3.Rubber \& plastics & $0.137(0.127)$ & $0.144(0.121)$ \\
4.Metal & $-0.100(0.143)$ & $-0.080(0.137)$ \\
5.Machinery & $0.199(0.153)$ & $0.228(0.146)$ \\
6.Electrical equip. & $-0.091(0.203)$ & $-0.044(0.191)$ \\
7.Medical tools & $-0.030(0.166)$ & $0.022(0.157)$ \\
8.Motor vehicles & $1.172^{* * *}(0.214)$ & $1.165^{* * *}(0.205)$ \\
9.Commerce & $0.204(0.142)$ & $0.215(0.135)$ \\
10.Software & $-0.121(0.220)$ & $-0.007(0.204)$ \\
11.R\&D & $0.296^{* *}(0.127)$ & $0.298^{* *}(0.122)$ \\
\hline 12.Architecture & 0.7271 & 0.7145 \\
\hline Constant & -307.842 & -269.21 \\
\hline Rho & -269.42 & -225.91 \\
\hline Log likelihood (null, constant & $92.43^{* * *}$ & $86.61 * * *$ \\
only) & 578.841 & 491.828 \\
\hline Log likelihood (model) & 665.754 & 578.740 \\
\hline Wald Chi2 & & \\
\hline AIC [20] & & \\
\hline BIC [20] & & \\
\hline (a) & & \\
\hline
\end{tabular}

(a) References are OPEN=0 (closed companies), Small and medium enterprises, Year 2005 and Industry $=0$ (Food $\&$ beverages) for OI, Size, Year and Industry respectively.

(b) ${ }^{*} \mathrm{p}<0.06,{ }^{* *} \mathrm{p}<0.05, * * * \mathrm{p}<0.01$. Standard errors in parentheses.

(c) AIC and BIC degrees of freedom in brackets 
Table 5. Main empirical results

\begin{tabular}{lll}
\hline Hypothesis & Relationship & Conclusion \\
\hline H1 & IMS is positively related to innovation efficiency. & Supported \\
\hline H2 & $\begin{array}{l}\text { Innovation efficiency has a positive effect on firm } \\
\text { performance. }\end{array}$ & Supported \\
\hline H3 & $\begin{array}{l}\text { Firms that adopt OI optimize their innovation } \\
\text { efficiency. This, in turn, leads efficient firms to } \\
\text { improve their performance. }\end{array}$ & Not supported \\
H3a & $\begin{array}{l}\text { OI in firms is positively related to innovation } \\
\text { efficiency. }\end{array}$ & (!) Not supported \\
H3b & $\begin{array}{l}\text { The positive effect of innovation efficiency on } \\
\text { firm performance is higher for firms that } \\
\text { practice OI than for closed firms. }\end{array}$ & (n.s.) Not supported \\
& (!) Contrary to the hypothesis; (n.s.) No significant relationship &
\end{tabular}

